\title{
Educação pública em risco em um cenário político de instabilidade e retrocessos
}

A RBPAE abre este número a exatos um ano e quatro meses do golpe de Estado impetrado no dia 31 de agosto de 2016, pelo Congresso Nacional, com a cumplicidade do Supremo Tribunal Federal (STF) e apoio incondicional dos grandes meios de comunicação, parte constitutiva da elite econômica brasileira e uma das beneficiárias do golpe de Estado. Desde o impeachment de Dilma Rousseff e a posse de Michel Temer, o desmonte do Estado de Direito avança, a soberania nacional escoa pelo ralo da história e, em nome de um pseudocombate à corrupção, liderado por juízes de primeira instância, assistimos atônitos ao maior ataque à classe trabalhadora da era Republicana e ao completo desrespeito à Constituição Federal de 1988.

A chamada reforma trabalhista, que se materializa nas leis $n^{\circ} 13.429$, de 31 de março de 2017 e n ${ }^{\circ} 13.467$, de 13 de julho de 2017, constitui uma afronta ao direito do trabalho, bem como aos sindicatos de todas as categorias profissionais, considerados elementos fundamentais do Estado democrático. A esse respeito, de acordo com Oliveira (2017) "A criação de empresas de trabalho temporário locadoras de mão de obra —, pela Lei n ${ }^{\circ} 13.429$, a autorização para a terceirização da atividade-fim (principal), os contratos autônomos e os intermitentes, pela Lei $n^{\circ}$. 13.467, representam a mais absoluta negação da Declaração de Filadélfia" (OLIVEIRA, 2017, p. 3), aprovada pela Organização Internacional do Trabalho (OIT) em 10 de maio 1944, na sua 26a Sessão, da qual o Brasil é signatário. De acordo com esta declaração "o trabalho não é uma mercadoria; e a liberdade de expressão e de associação é uma condição indispensável para um progresso constante"'.

Além disso, no que tange às implicações desta legislação na educação básica, a adoção do contrato intermitente é incompatível com o que preconiza o Art. 209 da CF, que exige cumprimento das normas gerais da educação nacional nos processos de avaliação. Se a principal atividade, do ensino, for executada por empresa terceirizada, sob que condições estes processos avaliativos serão realizados? Como os professores terceirizados poderão cumprir as tarefas que lhes são atribuídas pelo Art. 13 da Lei de Diretrizes e Bases da Educação Nacional

1 Publicação da Organização Internacional do Trabalho (OIT). Disponível em < http://www.dgert. gov.pt/declaracao-de-filadelfia> 
(LDB), se não lhes são dadas as condições concretas e objetivas para se dedicarem a estas atividades? Este Art. 13 estabelece que os professores devem

\begin{abstract}
I - participar da elaboração da proposta pedagógica do estabelecimento de ensino; II - elaborar e cumprir plano de trabalho, segundo a proposta pedagógica do estabelecimento de ensino; III - zelar pela aprendizagem dos alunos; IV estabelecer estratégias de recuperação para os alunos de menor rendimento; V ministrar os dias letivos e horas-aula estabelecidos, além de participar integralmente dos períodos dedicados ao planejamento, à avaliação e ao desenvolvimento profissional; VI - colaborar com as atividades de articulação da escola com as famílias e a comunidade (BRASIL, 1996).
\end{abstract}

No âmbito da educação superior também pairam algumas questões, dentre elas a que diz respeito à formação e titulação dos professores que, de acordo com o Art. 47, $\int 1^{\circ}$, da LDB, a IES deve definir e divulgar a qualificação dos professores, antes do início do semestre acadêmico. Como isso será possível se as instituições não os possuem e não podem interferir na gestão das empresas prestadoras de serviços, que os contratam e os substituem de acordo com seus próprios critérios?

Como cumprir as normas contidas do Art. 16 do Decreto no 5.773/2006 para os Planos de Desenvolvimento Institucional (PDIs), para efeito de credenciamento e recredenciamento institucional, que exigem a definição do perfil do corpo docente, indicando requisitos de titulação, experiência no magistério superior e experiência profissional não acadêmica, bem como os critérios de seleção e contratação, a existência de plano de carreira, o regime de trabalho e os procedimentos para substituição eventual dos professores do quadro? Como avaliar a IES e os seus cursos se os professores contratados são terceirizados? Qual será a relação de docentes, constante do cadastro nacional de docentes, exigida para reconhecimento de curso? Como o índice geral de curso (IGC) e o conceito preliminar de curso (CPC) serão calculados sem considerar o corpo docente? Como comprovar o regime de trabalho docente em tempo integral de quarenta horas semanais na mesma instituição, com no mínimo vinte horas semanais de dedicação ao planejamento e avaliação, estudos, pesquisas e atividades de extensão?

Não restam dúvidas, portanto, que o contrato autônomo, previsto no Art. 442-B da CLT, com a redação dada pela lei $n^{\circ} 13.467 / 2017$, não pode ser aplicado nas instituições de ensino, pois não há como conceber o trabalho de um professor de escola regular, de nível básico e superior, sem a presença dos elementos constitutivos do vínculo empregatício, especificados pelo Art. $3^{\circ}$ da CLT, que não foi alterado, quais sejam: pessoalidade, habitualidade, salário e subordinação jurídica. Como se viabilizaria o cumprimento das atribuições 
docentes, estipuladas pelo Art. 13 da LDB, por meio de contrato autônomo? Em que condições concretas se realizariam as reuniões pedagógicas, de colegiado/ conselhos com professores terceirizados? (OLIVEIRA, 2017).

Outro ponto importante que tem mobilizado as entidades educacionais, incluindo a ANPAE é o debate em torno do "Projeto Escola sem Partido" (PLS 193/2016, PL 1411/2015 e PL 867/2015), cujo principal objetivo é eliminar a discussão considerada "ideológica” e definir os conteúdos curriculares sob a ótica de uma pretensa neutralidade do conhecimento. Não restam dúvidas, entretanto, que se trata de um projeto que contraria o princípio constitucional do pluralismo de ideias e de concepções pedagógicas, assim como o da liberdade de aprender, ensinar, pesquisar e divulgar o pensamento, a arte e o saber, que considera como válidos determinados conteúdos que reforcem os princípios da ordem social e política estabelecida e como doutrinários aqueles que representam uma visão crítica e problematizadora desta mesma realidade. É negado, portanto, o princípio do contraditório, da pluralidade de pensamento e de ideias.

Tendo em vista a gravidade deste movimento, emergiu uma grande e extensa mobilização de entidades educacionais e movimentos sociais contestando os PLs e o ideal de educação que eles representam, por meio da divulgação de inúmeras notas de repúdio, promoção de eventos, debates, passeatas, tanto em redes sociais como nas ruas e diversos espaços públicos. Em Nota Técnica, o Ministério Público considerou que o PL Escola sem Partido é inconstitucional porque "está na contramão dos objetivos fundamentais da República Federativa do Brasil, especialmente os de 'construir uma sociedade livre, justa e solidária' e de 'promover o bem de todos, sem preconceitos de origem, raça, sexo, cor, idade e quaisquer outras formas de discriminação".

Entretanto, outros dois projetos idênticos tramitam na Câmara e no Senado Federal, de autoria do deputado Izalci Lucas (PSDB-DF) e do senador Magno Malta (PR-ES), respectivamente, que pretendem alterar a Lei de Diretrizes e Bases da Educação para a inclusão do "Programa Escola Sem Partido". Já o PL de autoria do deputado Rogério Marinho (PSDB-RN) pretende alterar o Código Penal propondo detenção de três meses a um ano para professor, coordenador, educador, orientador educacional ou psicólogo escolar que praticar o dito "assédio ideológico". Nesse sentido de acordo com Dutra (2017) "O transcurso das políticas educacionais em construção sofreu várias investidas de setores conservadores, especialmente de setores privatistas da educação que, aliados às bancadas fundamentalistas no Congresso Nacional, alcançaram força para aprovar retrocessos." A mesma autora também considera que

não é aleatório o fato de que o golpe do impeachment ocorrido no Brasil, fomentado pela elite patriarcal, conservadora e privatista, tem na educação seu principal alvo de retrocesso. A escolha de um ministro do partido herdeiro da Arena, partido 
sustentáculo da Ditadura Militar, o DEM, que entrou com ações na justiça contra o Programa Universidade para Todos (Prouni) e a Lei das Cotas é extremamente simbólica (DUTRA, 2017).

A institucionalização do "Programa Escola sem Partido", portanto, representa o desmonte do percurso de construção democrática no campo da educação nacional, desde o fim do período militar, constituindo-se em um violento ataque à liberdade de cátedra e ao princípio da gestão democrática da escola, que viola a Constituição e ignora a $\mathrm{LDB}$, que define a autonomia administrativa e pedagógica dos sistemas de ensino e orienta a elaboração de propostas curriculares com base nas diretrizes curriculares estabelecidas Conselho Nacional de Educação (CNE).

Para completar o cenário sombrio no campo das políticas educacionais, o CNE aprovou no dia 15 de dezembro de 2017, em caráter de urgência, a terceira versão da Base Nacional Comum Curricular (BNCC). Esta versão vem sendo construída a partir da configuração das políticas educacionais pós-golpe, sob a batuta do grupo que assumiu o MEC, constituído por uma coligação liberalconservadora representada pelo DEM-PSDB. Segundo Freitas (2017), neste processo

a educação infantil foi escolarizada (com a definição de objetivos em três faixas de idade e agora com a redução da idade limite para alfabetização), introduziram-se habilidades sócio-emocionais, além de outras iniciativas mais internas à constituição dos conhecimentos. Claro, na revisão de português final, encontraram alguns termos redundantes como "gênero" e "orientação sexual" e os retiraram (p. 3).

O que se observa nesta versão é uma adequação ao modo mais conservador de governo, de viés gerencial e afinado com os interesses de grupos privados, em especial da Fundação Lemann. Embora a construção de uma base nacional comum esteja prevista no PNE 2014-2024, e, portanto, seria o resultado de um grande esforço do coletivo das CONAES de 2010 e 2014, o que está em discussão não representa o que ficou definido nas Conferências.

Ao contrário, a atual BNCC

tem por fundamento uma concepção gerencialista autoritária que é dissimulada nesta argumentação de garantir direitos aos mais pobres. A intencionalidade da atual base é padronizar para poder cobrar da escola. Quando dizem que a BNCC garante direitos dos mais pobres, querem de fato significar que agora a escola será penalizada se não ensinar os pobres (ou os ricos) de acordo com tudo que a BNCC diz que têm direito - independentemente de terem ou não condições concretas para poder desempenhar seu trabalho. Para isso se está fazendo o ENAMEB - Exame 
Nacional do Magistério do Ensino Básico e realinhando os exames nacionais à BNCC. Portanto, a BNCC não pode ser examinada isoladamente, mas como a base de toda uma política de pressão sobre a escola e seus profissionais, que conduzirá à privatização e destruição da escola pública. (FREITAS, 2017, s/p)

Um excerto retirado da $3^{a}$ versão da BNCC confirma esta visão:

\begin{abstract}
A primeira tarefa de responsabilidade direta da União será a revisão da formação inicial e continuada dos professores para alinhá-las à BNCC. A ação nacional será crucial nessa iniciativa, já que se trata da esfera que responde pela regulação do ensino superior, nivel no qual se prepara grande parte desses profissionais. Diante das evidências sobre o peso do professor na determinação do desempenho do aluno e da escola de educação básica, essa é uma condição indispensável para a implementação da BNCC. (BRASIL, 2017, p.15).
\end{abstract}

Observa-se, portanto, que a BNCC está alinhada a outras políticas que contribuem para responsabilizar a escola e os professores e desresponsabilizar os governos: exames nacionais, produção de material didático e sistemas de ensino, avaliações de professores, normas para formação de professores, etc. Por fim a BNCC da forma como está apresentada nesta terceira versão representa a padronização do ensino que reforça a centralidade das avaliações nacionais (e internacionais) e demais instrumentos que são decorrentes da política educacional pautada em resultados. Pode-se supor ainda a sua vinculação direta com o movimento da Escola Sem Partido, tendo em vista o teor das modificações apresentadas na atual versão da BNCC, que excluíram todas as referências à diversidade de gênero e dos direitos humanos, pautas consideradas muito importantes pelo coletivo de movimentos sociais que incluem mulheres, comunidades LGBTT, minorias étnicas, associações científicas, fóruns populares, sindicatos de diversas categorias de trabalhadores, artistas e intelectuais, dentre outros.

Em meio a tantas pautas recessivas para a classe trabalhadora em geral e para os trabalhadores da educação em particular, o Banco Mundial publicou um relatório de um trabalho encomendado pelo governo no qual propõe um "ajuste justo" no campo da educação pública brasileira, que, em síntese, considera que os recursos financeiros aplicados na educação são altamente ineficientes em 50\% na educação superior pública e em 39\% na educação básica pública. Essas conclusões foram obtidas a partir da consideração apenas dos resultados do Enade e do Pisa sem considerar a história e a realidade social, econômica, cultural e territorial brasileira.

De posse dessas considerações, de acordo com Amaral (2017), o documento do Banco Mundial propõe ações que debilitarão ainda mais a educação pública brasileira. Na página 121 do documento, os autores afirmam que "os gastos 
públicos com o ensino superior também são altamente ineficientes, e quase 50\% dos recursos poderiam ser economizados". Para Amaral, aqui há uma inferência sem comprovação - "os gastos públicos são altamente ineficientes" - e uma conclusão absurda, que beira a irresponsabilidade - " $50 \%$ dos recursos das universidades públicas poderiam ser economizados". Isso implicaria em destruir o conjunto das 63 Universidades Federais em todo o território brasileiro. (AMARAL, 2017).

O segundo aspecto que Amaral destaca está na página 125 do documento, na qual os autores afirmam que "o baixo desempenho do sistema educacional brasileiro reflete-se nas altas taxas de reprovação e evasão escolar, apesar das baixas e decrescentes razões aluno-professor", isto implicaria em elevar a relação aluno-professor no Brasil, que já é maior que a média dos países da OCDE. No Brasil, em 2014 esta relação era de 21 alunos nos anos iniciais, 18 nos anos finais do ensino fundamental e 15 alunos no ensino médio, frente a 15, 13 e 13, respectivamente, média da OCDE (OCDE, 2017, p. 403).

Outro aspecto que chama a atenção no referido documento do BM está na página 127 e se refere aos salários dos professores. Os autores afirmam que "os salários iniciais dos professores do ensino básico encontram-se em linha com níveis internacionais (como percentual do PIB per capita)", em que se apresenta um erro conceitual que mistura percentuais relativos ao PIB com valores a serem pagos aos professores. Isso implica que não haveria a necessidade de se elevar os salários dos professores da educação básica brasileira? Em caso positivo para esta afirmação, estariam sendo contrariadas as metas e estratégias do PNE que preveem a valorização da carreira dos profissionais da educação em todos os níveis e modalidades educacionais.

O quarto aspecto que Amaral (2017) destaca se refere a questões de financiamento, contidas na página 130 do documento do BM. De acordo com os autores "a vinculação constitucional dos gastos em educação a $25 \%$ das receitas dos municípios também contribui para a ineficiência dos gastos". Neste aspecto novamente o documento incorre em um novo erro conceitual, pois não são esses os termos da vinculação constitucional contida no Art. 212 da Constituição Federal de 1988. Além disso, esta afirmação induz à conclusão de que a vinculação constitucional dos impostos para a educação pode ser eliminada, sem contudo, apresentarem nenhum dado concreto que corrobore a "conclusão" dos autores de que a vinculação contribui para a ineficiência dos gastos.

Por fim, Amaral também destaca um dos pontos chave do documento que prevê, na página 121, "a necessidade de introduzir a cobrança de mensalidades em universidades públicas para as famílias mais ricas" como forma de "se fazer justiça", cobrando de quem pode pagar. A cobrança de mensalidades dentro da lógica do Banco Mundial seria feita levando-se em conta a renda dos diversos 
estratos sociais da população, garantindo-se a gratuidade para a população de baixa renda. Entretanto, de acordo com uma estimativa realizada por Amaral (2017), levando-se em conta o perfil socioeconômico da população e dos estudantes matriculados nas IFES em 2014, "para ter uma pessoa da família estudando numa Universidade Federal, a mensalidade a ser paga deveria ser o equivalente a $24,2 \%$ da renda bruta familiar. Não há dúvida quanto à impossibilidade de se atingir esta meta num país em que concentração de renda é tão elevada" (AMARAL, 2017).

Portanto, podemos concluir que se estas recomendações forem atendidas, acopladas aos efeitos da Emenda Constitucional n $n^{\circ} 95$, que congela os recursos do Poder Executivo até 2036, a educação pública brasileira estará em risco e as metas do Plano Nacional de Educação 2014-2024 serão apenas uma carta de intenções, como já fora o PNE 2001-2010.

\section{DOSSIÊ: A NOVA GESTÃO PÚBLICA NO CONTEXTO ESCOLAR: INTERNACIONALIZAÇÃO DE UMA AGENDA PARA A EDUCAÇÃO DO SÉCULO XXI}

É neste contexto que apresentamos este dossiê, que marca a última edição impressa da RBPAE. O dossiê intitulado "A Nova Gestão Pública no contexto escolar: internacionalização de uma agenda para a educação do século XXI" tem justamente por objetivo contribuir para a discussão no campo da Administração Educacional indagando sobre a circulação de políticas em âmbito internacional que são incorporadas em contextos nacionais, sofrendo, obviamente adequações e recontextualizações. A pretensão é abordar uma discussão que se dá em âmbito internacional trazendo à luz múltiplas abordagens e reflexões sobre distintas realidades, mas ao mesmo tempo situando a problemática no cenário brasileiro. Assim, a temática do dossiê conversa muito de perto com a questão conjuntural enfrentada pelo país, e exposta acima, em pelo menos dois aspetos muito importantes: a expansão da privatização da educação como um fenômeno mundial que tem mobilizado um amplo debate em diferentes setores: acadêmico, sindical, governamental, etc.; e as formas dissimuladas dessa privatização, utilizando-se das expressões de Ball e Youdell (2006), que por meio da Nova Gestão Pública (NGP) vão contaminado as instituições estatais com os princípios da lógica privada.

Essas questões nos remetem a um debate urgente e necessário e discussão que está na ordem do dia, qual seja, a regulamentação da Meta 19 do PNE (Lei 13.005/2014) que prevê: "Assegurar condições, no prazo de 2 (dois) anos, para a efetivação da gestão democrática da educação, associada a critérios técnicos de mérito e desempenho e à consulta pública à comunidade escolar, no âmbito das escolas públicas, prevendo recursos e apoio técnico da União para tanto.” Apesar 
dos dois anos previstos terem se expirado em 2016, a meta segue como uma orientação normativa no contexto nacional, envolta as contradições do sistema federativo brasileiro e a enorme fragmentação e diversificação que apresenta.

Uma das problemáticas centrais que o dossiê busca enfrentar é justamente compreender em que medida a racionalidade da NGP tem sido incorporada pelos diferentes atores nas políticas educacionais, dos ministérios ao chão da escola, passando pelos órgãos intermediários. A disseminação da NGP nos processos de reforma do Estado tem sido um processo amplo que atinge um número considerável de países, neste dossiê apresentamos algumas reflexões sobre essas experiências em diferentes níveis e estágios. Verger e Normand (2015) assinalam que, nos últimos anos, a NGP tem penetrado com força na agenda educativa global, por ser este um setor com destacada dotação orçamentária. Afirmam ainda que, onde foi aplicada, a NGP alterou de maneira drástica a forma como se concebe a governança das instituições educativas, já que princípios como autonomia escolar, a prestação de contas, a gestão baseada em resultados e a liberdade de escolha escolar têm interferido profundamente em como se regulam, proveem e financiam os serviços educativos.

A adoção da NGP na educação trouxe mudanças importantes para a configuração atual dos sistemas educativos e das escolas. Contudo, essa não é uma discussão simples, pois envolve complexas relações o que exige grande esforço de análise para compreender em quais aspectos ela ganha maior aderência e porque seu discurso tem sido tão naturalizado. A NGP veio acompanhada de maior descentralização administrativa e financeira, que, de certa forma, "empoderaram" as escolas como unidade do sistema, atribuindo-lhes maior autonomia institucional e responsabilidades pelos seus processos. Ela veio também acompanhada da defesa de maior transparência nos serviços públicos, o que trouxe consigo as políticas de prestação de contas, o que no âmbito escolar foi traduzido em mais avaliação e responsabilização. A ênfase nas avaliações dos resultados acadêmicos tem dirigido cada vez mais a gestão escolar, passando a funcionar como um importante mecanismo de regulação do sistema. Essa tem sido a experiência observada em diferentes contextos nacionais, cada um com suas particularidades.

O diretor ou a diretora escolar sempre foi ator central no governo da escola (Carvalho, 2000), porém sua função tem se revestido ainda mais de importância a partir dessas mudanças. Por esta razão, neste dossiê procurou-se abordar desde o plano da macro política até o espaço micro da escola, buscando compreender desde as influências no plano internacional até a prática cotidiana da direção escolar, como a NGP perpassa esses espaços. Assim, este dossiê reúne um conjunto importante de autores nacionais e estrangeiros que têm produzido conhecimento a este respeito, pesquisado e debatido essas questões em diferentes 
aspectos e espaços dos sistemas educacionais. Os artigos aqui reunidos são resultados de estudos e pesquisas sobre as alterações sofridas pela gestão da educação dos ministérios às escolas, a partir da introdução da NGP.

$\mathrm{O}$ artigo intitulado $A$ modernização do sistema educacional na França: a Nova Gestão Pública entre a afirmação do Estado e o governo descentralizado, de Jean-Louis Derouet, traz uma importante contribuição sobre como os impactos da NGP em um sistema de tradição republicana em que a regulação é realizada por importantes órgãos profissionais, como a Inspeção Geral, e como ela penetra com o discurso da modernização, a cultura profissional docente resvalando no poder dos sindicatos.

Do outro lado do atlântico, Gary Anderson, com o artigo Privatizando subjetividades: como a Nova Gestão Pública (NGP) está criando o "novo" profissional da educação, baseando-se em pesquisa nas escolas de Nova York, vai demonstrar como a NGP afeta a subjetividade dos profissionais da educação, como professores e diretores sentem que não estão envolvidos em decisões que afetam suas vidas profissionais e como seu julgamento profissional é desrespeitado e seu trabalho degradado em uma cultura crescente de "auditoria".

A contribuição de Anne Barrère, com o artigo $A$ ação pedagógica dos gestores principais de instituições francesas: oportunidades e tensões baseia-se em uma pesquisa qualitativa sobre o trabalho dos dirigentes escolares na região norte da França. Suas análises centram-se, portanto, no chão da escola, buscando compreender os processos de mudança de uma gestão emergente da educação, a partir da experiência de trabalho do dia-a-dia das equipes de gestão e, em particular, analisando suas relações com os professores. A autora procura identificar as representações e as convicções dos dirigentes escolares sobre dois pilares da sua ação: a busca da eficiência e o envolvimento dos professores com a escola, bem como as principais tensões que enfrentam com suas novas missões de ensino.

O artigo de Toni Verger e Lluís Parcerisa, La globalización de la rendición de cuentas en el ámbito educativo: una revisión de factores y actores de difusión de politicas, ambos da Universidade Autônoma de Barcelona, é baseado em uma revisão bibliográfica em que analisam os fatores e condições que favoreceram a disseminação de políticas de prestação de contas em escala global e o papel desempenhado pelos organismos internacionais. A análise do papel dos organismos internacionais nessa questão é indispensável, pois estes influenciam sobremaneira na difusão dessa agenda. Os resultados mostram que a globalização da prestação de contas deve-se à confluência de uma grande variedade de fatores de natureza muto diferente, e identifica convergências e divergências entre esses organismos na promoção de reformas orientadas à prestação de contas. 
O artigo de Luís Miguel Carvalho e Estela Costa, Avaliação externa das escolas em Portugal: atores, conhecimentos, modos de regulação, centra-se na construção e reconstrução do modelo de avaliação externa das escolas em Portugal em dois momentos (2006 e 2011), pondo em evidência continuidades e mudanças relacionadas com os atores e com os conhecimentos mobilizados para a construção dos modelos avaliativos, bem como o fortalecimento da avaliação como dispositivo de regulação das práticas de administração das escolas.

O artigo de Dalila Andrade Oliveira, Alexandre Willian Duarte e Ana Maria Clementino, A Nova Gestão Pública no contexto escolar e os dilemas dos(as) diretores(as), apresenta resultados de pesquisa recente realizada em cinco capitais brasileiras sobre a percepção das direções escolares a respeito das mudanças introduzidas com a NGP nas diferentes redes públicas de ensino. As políticas desenvolvidas por essas redes em maior ou menor grau têm como foco os resultados, traduzidos em indicadores de eficiência da gestão escolar e que são obtidos por meio da avaliação do desempenho dos estudantes em testes padronizados. $\mathrm{O}$ artigo procura explorar os dilemas dos(as) diretores(as) ante a pressão por cumprimento de metas de resultados e o clamor vindo do entorno da escola por maior inclusão social.

O artigo de Iana Gomes de Lima e Luís Armando Gandin, Gerencialismo e dispersão de poder na relação Estado-educação: as traduções e os hibridismos do caso brasileiro tem como objetivo analisar a presença do gerencialismo no Estado brasileiro, examinando, em particular, uma de suas características centrais: a dispersão de poder. Demonstra que a dispersão de poder se faz presente na relação entre Estado e educação no Brasil, mas consideram que isso não se faz de maneira linear. Apoiando-se em autores que são referência no campo, Lima e Gandin concluem que isso se aplica ao caso brasileiro, tendo como objeto a análise das políticas educacionais recentes, em que há sempre um processo de tradução e não mera transposição de concepções dominantes sobre como o Estado deve se organizar.

A contribuição que traz o artigo de Luiz Fernando da Silva e Adriana Duarte, intitulado Gestão por resultados e participação da comunidade escolar: a experiência da rede municipal de educação de Belo Horizonte, é justamente a análise da repercussão de um programa específico (BH metas e resultados) na gestão das escolas públicas municipais, com foco na participação da comunidade escolar. O estudo desenvolvido pelos autores mostrou que a "participação" da comunidade escolar tem-se aproximado da perspectiva gerencial de participação, centralizando a gestão no diretor. Identificou sobreposição de regulamentos, uns ampliando a participação da comunidade escolar na gestão, outros reduzindo-a. 
O artigo de Celso Luiz Aparecido Conti, Emília Freitas de Lima e Renata Maria Moschen Nascente, Visões de diretoras de escola sobre políticas públicas e determinaçoes legais educacionais, é resultado de pesquisa de natureza exploratória, que analisa a visão de diretoras de escolas públicas de Ensino Fundamental do estado de São Paulo acerca de políticas públicas e determinações legais educacionais. Os resultados revelam visões positivas da quase totalidade das diretoras em relação às determinações legais e às políticas educacionais estudadas, e uma gestão escolar baseada em lógica de controle em padrões hierarquizados mesclada com elementos do gerencialismo.

$\mathrm{O}$ artigo Sistemas de avaliação em larga escala e repercussões em diferentes contextos escolares: limites da padronização gerencialista, de autoria de Andressa Aita Ivo e Álvaro Moreira Hypólito, discute como os sistemas de avaliação em larga escala, em especial a Prova Brasil, repercutem em espaços escolares diferentes. A partir de estudo qualitativo em duas escolas, situadas na região mais ao sul do país, os relatos dos gestores e professoras entrevistadas mostram como a política de índices de qualidade desconsidera as especificidades locais, reforça a competição e a busca desenfreada das escolas por resultados.

Enquanto o artigo de Lúcia de Fátima Melo e Mário Roberto Machado Torres, A função de diretor de escola pública no estado do acre e sua politica de formação e remuneração, portanto, na região norte do país, chega a resultados muito próximos. A análise se fundamenta em pesquisa bibliográfica, documental e empírica que demonstra certa insatisfação dos sujeitos que estão envolvidos na gestão escolar com aspectos importantes que envolvem sua função, tais como a remuneração, a formação que recebem para o exercício diante das responsabilidades que passaram a ter no conjunto das reformas educacionais ensejadas pela Nova Gestão Pública.

E, fechando o dossiê, o artigo de Luzenir Poli e Rosilene Lagares, Dilemas da gestão democrática da educação frente ao contexto da Nova Gestão Pública, remete à problemática central deste debate que é a tensão entre a gestão democrática e os princípios da NGP no coração da escola. As autoras discutem aspectos que têm favorecido ou dificultado a democracia, os conflitos, dilemas, riscos de retrocessos autocráticos, apontando a necessidade de análise e esforço para contrapô-los.

Por fim, é importante mencionar que a proposta deste dossiê surgiu no âmbito de uma parceria que tem sido desenvolvida nos últimos anos entre pesquisadores latino-americanos e europeus, e que tem como objeto o estudo dos efeitos das políticas educativas na reestruturação da profissão docente frente aos processos de globalização que determinam, cada vez mais, a agenda internacional da educação. O dossié reune assim, um grupo de autores com um histórico no estudo da política educativa em seus próprios campos nacionais, mas também num âmbito internacional, em especial aqueles que integram diretamente a rede 
de pesquisa internacional intitulada Globalização, políticas de educação e a reestruturação das profissões da World Educational Research Association (WERA).

O que este dossiê explora e expõe é justamente o que há de comum e diferente entre as experiências nacionais, mas sobressaltando uma circulação que transcende essas fronteiras e que demonstra que estamos face à implementação de um repertório de tecnologias e políticas, incorporados em grande medida pela NGP, e sobre os quais as organizações internacionais jogam um papel importante em sua difusão no plano internacional, com uma repercussão direta sobre os sistemas educacionais. A assimilação e interpretação desse repertório apresentam variações de acordo com os contextos de cada país, exigindo o conhecimento mais cuidadoso de cada realidade nacional em diferentes dimensões.

Assim, a expectativa é que este dossiê possa contribuir para o amadurecimento deste debate no contexto brasileiro e em outras realidades nacionais, em especial, nos importantes espaços que nos oferece a Associação Nacional de Política e Administração da Educação, a ANPAE, que cumpre historicamente papel de destaque no debate político-acadêmico sobre a agenda da educação.

\section{REFERENNCIAS}

AMARAL, Nelson Cardoso. Uma análise do documento "Um Ajuste Justo: análise da eficiência e equidade do gasto público no Brasil". Disponível em: https://avaliacaoeducacional.files.wordpress.com/2017/11/analise-criticabm-2017.pdf2017. Acesso em: 15 dez. 2017.

BANCO MUNDIAL, Um Ajuste Justo: Análise da eficiência e equidade do gasto público no Brasil. Disponível em: http://documents.worldbank.org/curated/ pt/884871511196609355/Volume-I-s\%C3\%ADntese. Acesso em 18 dez. 2017.

Base Nacional Comum Curricular (terceira versão). Disponível em: http:// basenacionalcomum.mec.gov.br/images/BNCC_publicacao.pdf. Acesso em: 17 dez. 2017.

BRASIL. Constituição da República Federativa do Brasil. Supremo Tribunal Federal. Disponível em http://www.stf.jus.br/arquivo/cms/ legislacaoConstituicao/anexo/CF.pdf. Acesso em: 15 dez 2017. 
. Lei no 9394 de 20 de dezembro de 1996. Estabelece as Diretrizes e Bases da Educação Nacional. Brasília: Diário Oficial [da] República Federativa do Brasil, Brasília, 23 dez. 1996.

Lei $\mathrm{n}^{\circ}$ 13.429, de 31 de março de 2017. Altera dispositivos da Lei no 6.019, de 3 de janeiro de 1974, que dispõe sobre o trabalho temporário nas empresas urbanas e dá outras providências; e dispõe sobre as relações de trabalho na empresa de prestação de serviços a terceiros. Diário Oficial [da] República Federativa do Brasil, Brasília, 31 mar. 2017.

. Lei no ${ }^{\circ}$ 13.467, de 13 de julho de 2017. Altera a Consolidação das Leis do Trabalho (CLT), aprovada pelo Decreto-Lei no 5.452, de 1o de maio de 1943, e as Leis nos 6.019, de 03 de janeiro de 1974, 8.036, de 11 de maio de 1990, e 8.212, de 24 de julho de 1991, a fim de adequar a legislação às novas relações de trabalho. Diário Oficial [da] República Federativa do Brasil, Brasilia, 14 jul. 2017.

. Decreto no 5.773, de 09 de maio de 2006. Dispõe sobre o exercício das funções de regulação, supervisão e avaliação de instituições de educação superior e cursos superiores de graduação e seqüenciais no sistema federal de ensino. Diário Oficial [da] República Federativa do Brasil, Brasília, 10 mai. 2006.

. Decreto-Lei no 5.453, de 01 de maio de 1943. Consolidação das Leis do Trabalho. Diário Oficial [da] República Federativa do Brasil, Brasília, 09 ago. 1943.

CARVALHO, L.M. O Senhor Director: fragmentos de uma história de actores e práticas escolares em Portugal. Educação e Pesquisa. Vol. 26 no.2 São Paulo Jul/Dec. 2000.

DUTRA, Claudia; MORENO, Camila. Escola Sem Partido: estratégia golpista para calar a educação. Disponível em: https://www.cartacapital. com.br/educacao/escola-sem-partido-estrategia-golpista-para-calar-a-educacao. Acesso em: 15 dez. 2017.

FREITAS, Luis Carlos. BNCC: uma base para o gerencialismo populista. Disponível em: https://avaliacaoeducacional.com/2017/04/07/bncc-uma-basepara-o-gerencialismo-populista/. Acesso em 15 dez. 2017. 
OLIVEIRA, D. A. Nova Gestão Pública E Governos Democrático-Populares: contradições entre a busca da eficiência e a ampliação do direito à educação. Educação \& Sociedade. Vol.36 no.132. Campinas jul./set. 2015.

OLIVEIRA, J. G. S. A incompatibilidade da reforma trabalhista e da terceirização com o ensino. Disponível em: <http://www.sinpro-abc.org.br/ index.php/component/content/article/44-destaque/2638-reforma-trabalhistax-ensino.html, consulta em 12 dez 2017.

OCDE. Education at a Glance 2016: OECD indicators. Disponível em: http:/ / www.oecd.org/edu/education-at-a-glance-19991487.htm. Acesso em: 15 dez. 2017.

VERGER, A. \& NORMAND, R. Nueva gestión pública y educación: Elementos teóricos y conceptuales para el estudio de un modelo de reforma educativa global. Educação \& Sociedade. Vol.36 no.132. Campinas jul./set. 2015.

\section{Dalila Andrade Oliveira \\ Organizadora do dossiê}

Lúcia Maria de Assis

Editora

Daniela da Costa Britto Pereira Lima

Editora Associada 